Original Research

\title{
Using DPSEEA Framework to Investigate the Relation between Arsenic Concentration Values in Waters and Cancer Rates in AP Vojvodina (North Serbia)
}

\author{
Emina Kričkovič́ ${ }^{*}$, Ivan Novković ${ }^{1}$, Tin Lukić ${ }^{2}$ Zoran Kričković3 \\ ${ }^{1}$ University of Belgrade, Faculty of Geography, Studentski trg 3/3, Serbia \\ ${ }^{2}$ University of Novi Sad, Faculty of Sciences, Department of Geography, Tourism and Hotel Management, \\ Trg Dositeja Obradovića 3, Serbia \\ ${ }^{3}$ Military Geographical Institute, Ministry of Defence of the Republic of Serbia, Mije Kovačevića 5, Serbia
}

Received: 31 August 2021

Accepted: 13 November 2021

\begin{abstract}
Naturally high arsenic concentrations are characteristic for the ground water of the Pannonian Basin which covers parts of Hungary, Romania, Croatia, Serbia, and Slovakia. The aim of this study is to empirically test the relation between arsenic concentration values in water and cancer rates (lung and bladder cancer) using the well-established cause-effect framework (model) of Driving force-Pressure-State-Exposure-Effect-Action (DPSEEA) and systematically collected data in the AP Vojvodina (Northern Serbia). Two models were tested in this study. The first one was the Three-Element Model used for analysing the linkage between the state element (arsenic concentration values), the exposure element (water access), and the effect element (cancer rates). The second model was the Effect-Action Model for the analysis of the association between the effect element (cancer rates) and the action element (monitoring intensity). Both models confirm the intrinsic validity of the four elements of the DPSEEA framework. A linear function tested in the second model suggests that the association is not a simple, linear relationship between the four elements, but rather a more complex interaction. Research in this field may find a wider application in improving the health care management in Serbia.
\end{abstract}

Keywords: DPSEEA framework, environmental health, AP Vojvodina, arsenic, lung cancer, bladder cancer

*e-mail: memina1989@gmail.com 


\section{Introduction}

This study was conducted as part of the research on the influence of the geographic-medical factors on public health in the Republic of Serbia's Autonomous Province of Vojvodina (the AP Vojvodina). The aim was to empirically test the relation between arsenic concentration values in surface and ground water and cancer diseases, using the cause-effect framework (model) of Driving force-Pressure-State-ExposureEffect-Action (DPSEEA), now commonly accepted in the AP Vojvodina. This was done by examining and quantifying the relationship between the four elements within the DPSEEA framework: the state (arsenic concentration values), the exposure (water access), the effect (malignant diseases - bladder and lung cancer), and the action (monitoring the levels of arsenic concentration in water). The model, presented in Fig. 1, is named by the starting letters of its structure elements (the DPSEEA-model): D - driving force; $\mathrm{P}$ - pressure; $\mathrm{S}$ - situation (environment status); $\mathrm{E}$ - exposure; E - effects, and A - actions (which should be conducted in a public health system) [1].

This model is beneficial since it comprises a wide spectrum of potential forces (harmful effects) and the ensuring public actions, bringing together professionals, field workers, laboratory workforce as well as stakeholders in the field of environment management and public health in order to deal with emerging problems in a comprehensive manner [2, 3]. According to the World Health Organisations' (WHO) guidelines for drinking water, the extended set of the Environmental Health Indicators consists of: state (exceedance of water threshold values), exposure (access to safe drinking-water and sanitation), effect (number of cases of proven water-borne diseases), and action (water quality monitoring) [4]. In this study, the DPSEEA framework is used following the examples of good practice mentioned in the WHO report "Environmental

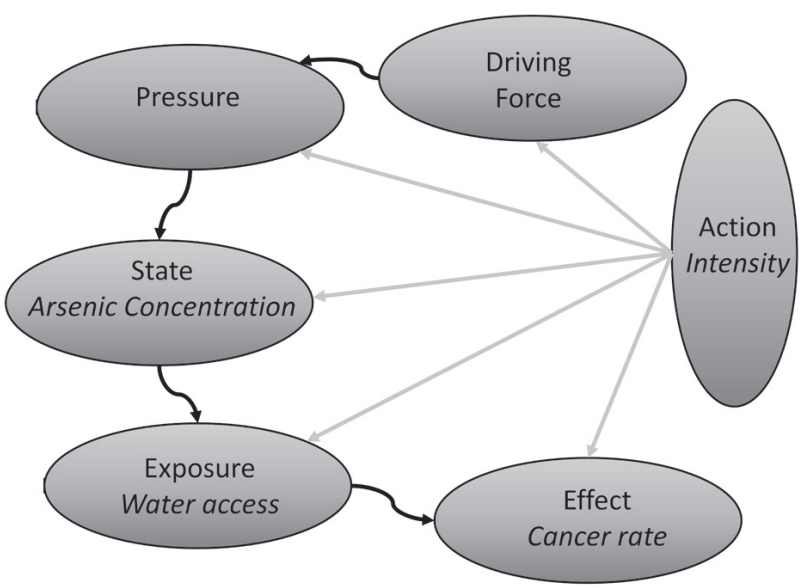

Fig. 1. DPSEEA framework used for the relation between a high level of arsenic concentration, drinking water access and a cancer rate.
Health Indicators for Europe" (with a successful utilization of the proposed methodology in order to comprehend problems or conceptualize indicators for sustainability assessments [4]). On the other hand, there are not so many regional studies using the DPSEEA framework to determine the driving forces or pressures related to specific geographic-medical issues.

According to the World Cancer Research Fund, Serbia is among the countries with the highest cancer rates (the 18th place with the rate of 307.9 per 100,000 in 2018) [5]. Cancer is a disease of unknown etiology, and it is not possible to single out only one factor influencing its occurrence. There are numerous studies in Serbia regarding the causes of high cancer rates. In the "Cancer Mortality in Serbia 1991-2015" study, the overall cancer rate for this period was 294.7 per 100,000 [6]. In the same study, it was stated that bladder cancer was the only cancer for which an upward trend (by $+0.9 \%$ per year) was seen in both sexes equally and continuously during the entire studied period [6].

According to the WHO, arsenic is a systemic poison, the continued ingestion of which can lead to a wide range of diseases and premature death [7]. Besides skin lesions, the symptoms of exposure to arsenic include skin, lung and bladder cancers as well as gastro-intestinal, cardio-vascular, and pulmonary conditions [7]. Arsenic minerals can be found in a variety of geological environments, including igneous, sedimentary, and metamorphic rocks [8, 9]. Arsenic is a ubiquitous element present in various compounds throughout the Earth's crust [10]. Naturally high arsenic concentration are also characteristic for the Pannonian Basin's ground water covering parts of Hungary, Romania, Croatia, Serbia, and Slovakia. The types and geochemical compositions of ground water in this area are strictly defined by sediment and paleogeography factors [11]. The geologic origin of arsenic is a consequence of clay decomposition, and that is how it is possible to explain the presence of high arsenic concentrations in the clay-rich soil of the AP Vojvodina (Northern Serbia).

The International Agency for Research on Cancer (IARC) has classified inorganic arsenic in drinking water as a Group 1 carcinogen [12]. It is well known that chronic exposure to high levels of arsenic causes a wide variety of serious health problems in humans. These problems include dermal changes (pigmentation, hyperkeratosis, and ulceration), gastrointestinal effects (stomach pain, nausea, vomiting, and diarrhea), neurological damage, cardiovascular problems (high blood pressure, heart attack, and stroke), various types of cancer (skin, bladder, lung, kidney, and other organs), and respiratory, pulmonary, hematological, hepatic, renal, developmental, reproductive, immunological, genotoxic, and mutagenic effects [9, 13-16].

There are few studies in Serbia linking arsenic in water with cancer. Smith A. et al. (1992) used large population studies in an area of Taiwan with high arsenic levels in well water $(170-800 \mu / \mathrm{L})$ to establish 
dose-response relationships between cancer risks and the concentration of inorganic arsenic naturally present in water supplies [10]. Subsequent investigations have confirmed that ingestion of inorganic arsenic can cause skin cancer and that inhalation of inorganic arsenic can cause lung cancer $[10,17]$. To date, epidemiological studies of populations exposed to high levels of inorganic arsenic have shown strong associations and dose-response relationships between arsenic in drinking water and bladder cancer as well as potential associations with kidney cancer [18, 19]. In the study entitled "Arsenic in drinking water and urinary tract cancers: a systematic review of 30 years of epidemiological evidence", it is stated that epidemiological studies provide extensive evidence that supports a causal association between exposure to higher levels of arsenic concentrations in drinking water and the risk of developing bladder cancer or dying from it [19]. This study also emphasizes that health effects on the population remain uncertain at lower levels of arsenic exposure in drinking water [19]. Arsenic contamination of ground water has become a serious environmental health problem in Bangladesh [20]. In order to compare risks of various internal organ cancers induced by ingested inorganic arsenic and to assess the differences in risks between males and females, Chen, et al. (1992) calculated cancer potency indices using the Armitage-Doll multistage model and the mortality rates among residents in an endemic area of chronic arsenicism on the southwest coast of Taiwan in the study "Cancer potential in liver, lung, bladder and kidney due to ingested inorganic arsenic in drinking water" [21]. Based on a total of 898,806 person-years as well as on 202 liver cancer, 304 lung cancer, 202 bladder cancer, and 64 kidney cancer deaths, a significant doseresponse relationship was observed between the arsenic level in drinking water and the mortality of the cancers [21].

Given that the DPSEEA framework is a popular model for supporting a decision-making process to reduce human disease burdens [4, 22-25] and since it allows the interpretation of complex environmental health issues by demonstrating clearly the links and relationships between the environment and human health [26], this framework has been used to test the relation between the arsenic level in drinking water and the cancer rates in the AP Vojvodina (Northern Serbia). Also, a spatial analysis of the distribution of the disease is important from biomedical, economic, and behavioral aspects, especially in Serbia where a complex health geography approach is still rather underdeveloped in comparison to other EU countries.

\section{Materials and Methods}

The study area covers the Autonomous Province of Vojvodina (Northern Serbia). The province is located in Southeast Europe, in the Balkan Peninsula and covers the southern part of the Pannonian Basin, i.e. the northern part of the Republic of Serbia. It is situated between $44^{\circ} 38^{\prime}$ and $46^{\circ} 10^{\prime} \mathrm{N}$ and $18^{\circ}$

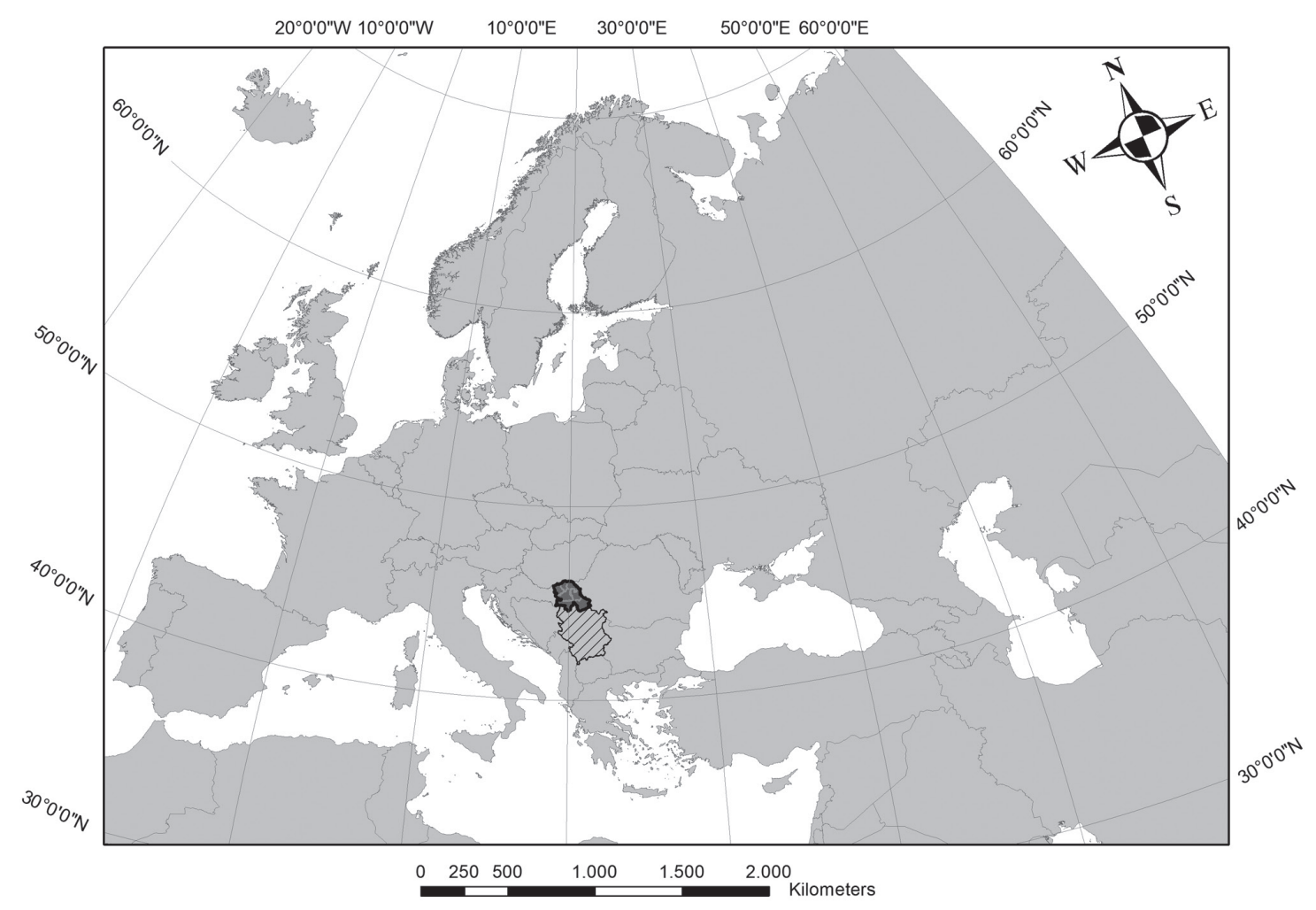

Fig. 2. Study area position in Europe and in Serbia. 
$10^{\prime}$ and $21^{\circ} 15^{\prime} \mathrm{E}$. The territory of the AP Vojvodina represents a contact zone between the Balkan Peninsula and Central Europe considering a wider geographical context. In this sense, it presents a natural overpass between Central and Western Europe, on the one hand, and the Balkan Peninsula and the Middle East, on the other hand. Fig. 2 shows the position of this province in Europe and in Serbia.

This study is primarily designed to test the relation between arsenic concentrations in surface/ground water and cancer rates using the DPSEEA framework. The four elements represent different stages of the framework. These elements have been adjusted to the Serbian context mostly reflecting data availability. Within the DPSEEA framework, the following elements are identified: State - arsenic concentrations in surface and ground water, Exposure - access to safe drinking water, Effect - lung and bladder cancer rates, and Action - monitoring intensity.

The Autonomous Province of Vojvodina has a population of 1.9 million and is divided in seven counties. Data on all elements was collected at the county level over a period of three consecutive years, 2016-2018. At the time of the study development, the county level was the smallest spatial unit for which data for all four elements was available.

\section{State: the Concentration of Arsenic in Surface and Ground Water}

According to the WHO's Guidelines for Drinking Water Quality, the most important routes of exposure to arsenic are through food and drinking water [27]. Also, by the UNICEF's and WHO's Guidance on the Investigation \& Mitigation of Arsenic Contamination in establishing health outcome targets, arsenic in food is particularly important in areas where arsenic is present in irrigation water [28]. That is why, for the state element, this study used arsenic concentration values in surface and ground water. According to the Serbian regulations for Class I surface water, suitable for irrigation and drinking, after all required treatments, the threshold value for arsenic concentration is lower than $5 \mu \mathrm{g} / 1$ [29].

The data used was taken from the Reports on the quality monitoring of surface and ground water in the period from 2012 to 2018, issued by the Serbian Environmental Protection Agency (SEPA) [30-36]. The values of the arsenic concentration at the county level were established through their mean annual values, as well as through their mean maximum values in surface and ground water. The values from all measuring stations were used and the number of measurements was summarized. The reference used for these measurements was UP $1.37 / \mathrm{PC} 12$, the method used for measurements was inductively coupled plasmamass spectrometry according to EPA 6020 A standard, and the concentration was measured in $[\mu \mathrm{g} / 1]$ units.

\section{Exposure: Number of Population with Safe Water}

According to the $\mathrm{WHO}$, within the issue related to access to safe drinking water, the percentage of households supplied with piped water is defined as exposure within the DPSEEA framework [4]. The number of the population with accessibility to "safe water" (non-contaminated water) was gathered through the assessment of drinking water quality in the official publications "Population Health Status of Vojvodina" [38-44]. The estimation at the settlement level was performed using the number of samples where exceeded values of arsenic were registered. The population number for specific settlements was taken from the 2011 census [37]. On the other hand, the number of the population using "unsafe water" for specific settlements was summarised at the county level. These numbers were used to aggregate the percentage of the total population by districts.

In accordance with local regulations, the samples for water quality testing were taken from purified chlorinated drinking water, unpurified chlorinated, untreated water, as well as from water from eco fountains and public wells. It is an important fact that only in one county in the AP Vojvodina there is a public water supply system which supplies population with purified chlorinated drinking water. In all other counties, the population is supplied with other above mentioned methods of water supply. The data, obtained from 2012 to 2018, was published by the Institute of Public Health of the AP Vojvodina in their annual reports [38-44].

\section{Effect: Cancer Rates}

The data related to cancer rates and used for this study was also obtained from the Institute of Public Health of the AP Vojvodina and the Institute of Public Health of Serbia "Dr Milan Jovanovic Batut" [3847]. Due to the lack of data for all cancer rates related to long term exposure to arsenic, only lung and bladder cancer rates were taken into consideration. The element used in this study comprises the summarised annual lung and bladder cancer rates per 100,000 by county (for both men and women). At the county level, the data is available only for the period from 2016 to 2018 [45-47]. As for all other years, the rates refer to the entire territory of the AP Vojvodina, and the statistic model used in this study showed that it was only possible to determine the relation at the county level, and not for the whole territory of the AP Vojvodina. Therefore, this study deals with three consecutive years and not more, although the cancer rate data was collected for previous years as well.

\section{Action: Monitoring Intensity}

The data on the number of arsenic concentration measurements was obtained from the Reports on 
the quality monitoring of surface and ground water in the period from 2016 to 2018, issued by SEPA [30-32]. In the years preceding the mentioned period, the number of measurements was very low, as well as the arsenic concentration measured. Then, the following year, the arsenic concentration was very high and the number of measurements for that year was at the same level as for the next one or for some previous years, so it was not possible to obtain data for all available years because the method used was not consistent.

\section{Analysis}

The data for each of the four elements was plotted as histograms and mapped by [26] county to illustrate the spatial distribution of the elements across the AP Vojvodina. A trend analysis was conducted to assess a temporal variation of each element over the three-year period.

Poisson regression modelling was used to assess the association between the above-mentioned elements within the DPSEEA framework [26]. This allows the analysis of dependent variables which follow the Poisson distribution, i.e. a distribution frequently encountered when counting a number of events, or concerning the rate of occurrence with nonnegative integers [26]. For this study, two statistical models were used. The first model assessed the relationships between the effect [26] element (cancer rates) and the influence on it from: a) the state [26] element (arsenic concentration values) and b) the exposure element (water access) [26]. The hypothesis was that an increase in the cancer rates would be associated with an increase in the arsenic concentration values and a decrease in water access, as shown in Fig. 3.

The second model assessed the relationship between the effect element [26] (cancer rates) and the action element (monitoring intensity) [26]. The hypothesis was that an increase in [26] the cancer rates would be followed by an increase in the intensity of monitoring,

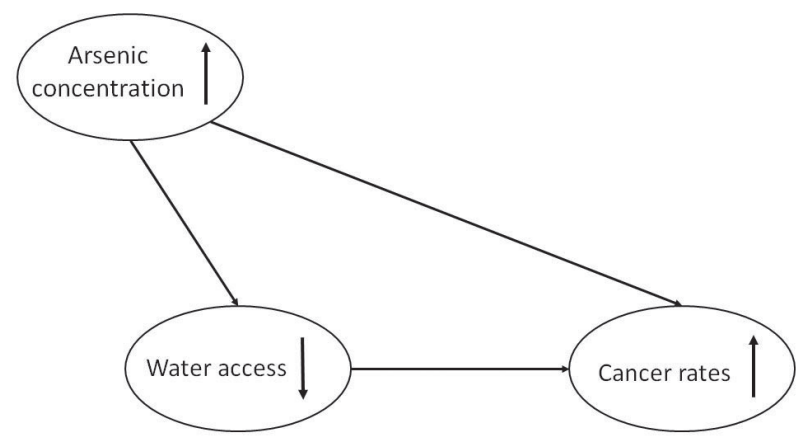

Fig. 3. MODEL 1 scheme: Three-Element Model illustrating the association between the state element (arsenic concentration), the exposure element (water access), and the effect element (cancer rates). as shown in Fig. 4. The Poisson regression model, which was used for both models, assumes that:

$$
\log \left(\_\right)=\_ \text {o }+ \text { iXi }+\ldots+\ldots \mathrm{nXn},[26]
$$

where _ is (1) cancer rates or (2) intensity of monitoring, $\mathrm{Xi}$ to $\mathrm{X} n$ are the predictor variables, $\mathrm{o}$ is the intercept, and $\mathrm{i}_{\mathrm{i}}$ is the regression coefficient for the predictor variable i, with $i>1$ [26]. Since a Poisson variable is assumed to have a mean $>0$, log transformation ensures that the model-based predictions of rates are constrained to be greater than, or equal to, zero. [26]. A P-value of less than 0.05 was considered statistically significant in this study [26].

For the second model, contrary to the model mentioned above, a simple linear relation between the two elements was tested first, by a simple explicit function $\mathrm{y}=\mathrm{kx}+\mathrm{n}$. A correlation of -1 shows a perfect negative correlation, while a correlation of 1 shows a perfect positive correlation. A correlation of 0 shows no linear relationship between the movements of the two variables. Statistical analyses were performed using the $\mathrm{R}$ programming language in computer software $\mathrm{R} / \mathrm{R}$ Studio. Since the use of the geographic information system (GIS) for spatial representation of diseases and conditions in the health sector (government, provinces, municipalities) of the given population can contribute to its intensive development and applicative importance, the ArcMap software was applied.

\section{Results and Discussion}

\section{Results}

Table 1 and Fig. 8 illustrate the nationwide temporal and spatial distribution of all four elements over the 3-year period, 2016-2018.

Over the time, the state element, i.e. the average annual arsenic concentration values per county has increased, except for one county, indicating that the quality of monitoring has improved. Fig. 5 shows the mean and maximum arsenic concentration values per county, indicating that the highest arsenic concentrations were measured in North Banat county, while some measurements influenced the averages of the maximum values to be higher than the average of the mean values for West Bačka county. The average mean value of arsenic (As) concentration for North

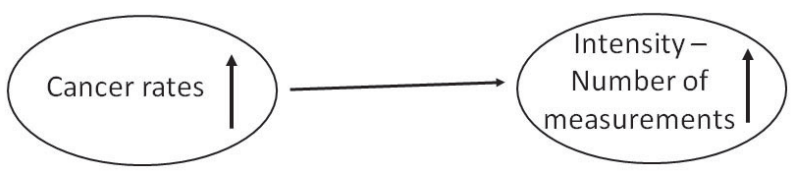

Fig. 4. MODEL 2 scheme: Effect-Action Model illustrating the association between the effect element (cancer rates) and the action element (monitoring intensity). 
a)

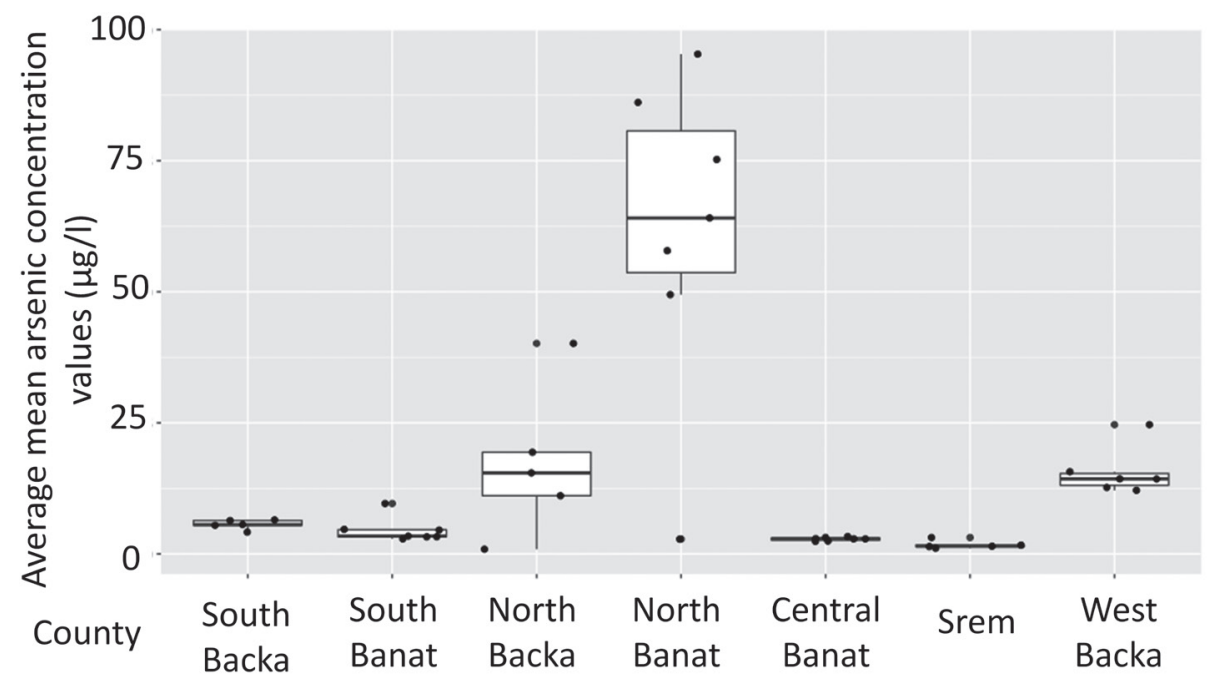

b)

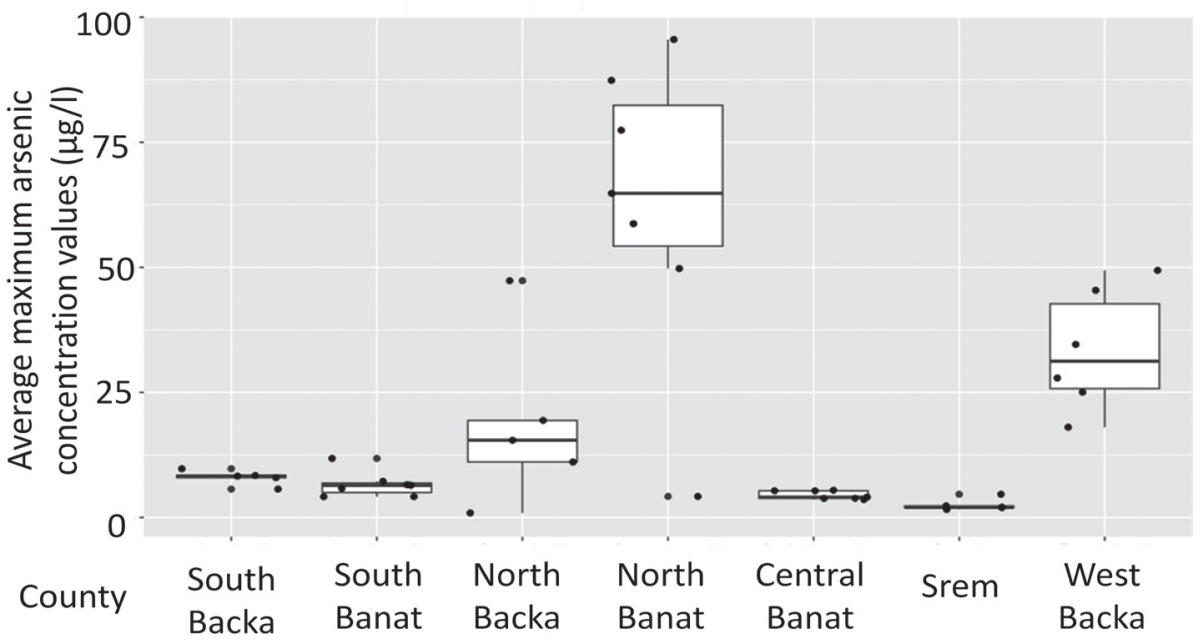

Fig. 5. a) Average mean arsenic concentration values per county, b) Average maximum arsenic concentration values per county.

Banat county during the 2012-2018 period was 61.55 $\mu \mathrm{g} / 1$, while the average maximum value was $62.54 \mu \mathrm{g} / 1$. The measured average maximum values of As concentration for West Bačka county were $45.41 \mu \mathrm{g} / 1$ in 2018 and $49.39 \mu \mathrm{g} / \mathrm{l}$ in 2014, although the average maximum value of As concentration during the observed period was somewhat lower $(18.84 \mu \mathrm{g} / \mathrm{l})$. The average mean value of As concentration in this district for the same period was $17.4 \mu \mathrm{g} / \mathrm{l}$. The lowest arsenic concentrations were measured in Srem county. The average mean value for this district was $1.76 \mu \mathrm{g} / \mathrm{l}$, and the average maximum value of As concentration was $2.52 \mu \mathrm{g} / 1$.

With regard to the Serbian regulations [29] on the threshold values of As concentration (5 $\mu \mathrm{g} / \mathrm{l}$ ), the average mean and average maximum values of As concentrations are under this limit in only three (out of seven) counties. Regarding the WHO threshold values $(10 \mu \mathrm{g} / \mathrm{l})$, four (out of seven) districts are under the defined limit. The geographical distribution of the mean arsenic concentration values are shown in Fig. 8a).
In order to use the effect element, i.e. cancer rates, and the available data on the number of new cancer cases and average arsenic concentrations, the number of new cancer cases per 100,000 population by county (for lung and bladder cancer) was taken. The number of new cases of lung and bladder cancer for both men and women for each county was summarized. Over time, the cancer rate for these diseases has increased, which could be seen in Fig. 6a). In the period from 2016 to 2018, the highest cancer rate was recorded in West Bačka county, with an average of 320.47 new cancer cases per 100,000 population. In the same period, the lowest cancer rate was recorded in South Bačka county, with an average of 235.53 new cases. The largest increase in cancer rate was recorded in Central Banat county (varying from 301.4 in 2016 to 357.6 new cancer cases per 100,000 population in 2018), while the lowest in-crease in cancer rate was recorded in South Bačka county (varying from 229.2 in 2016 to 248.2 new cancer cases per 100,000 population in 2018). The geographical distribution of the cancer rates is shown in Fig 8c). 


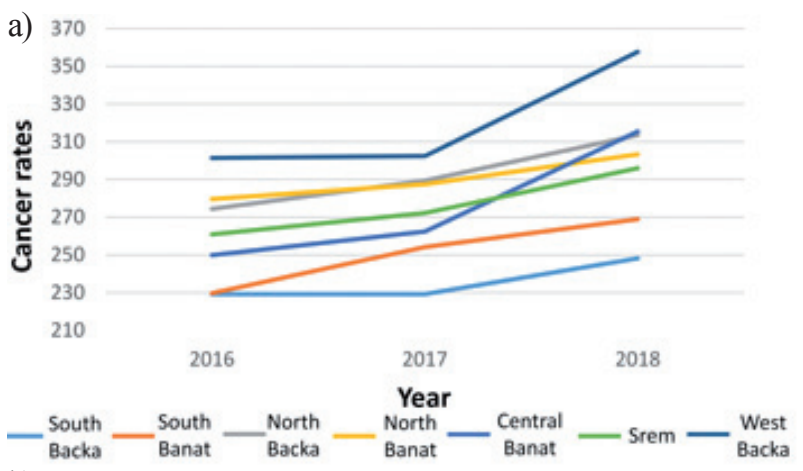

b)

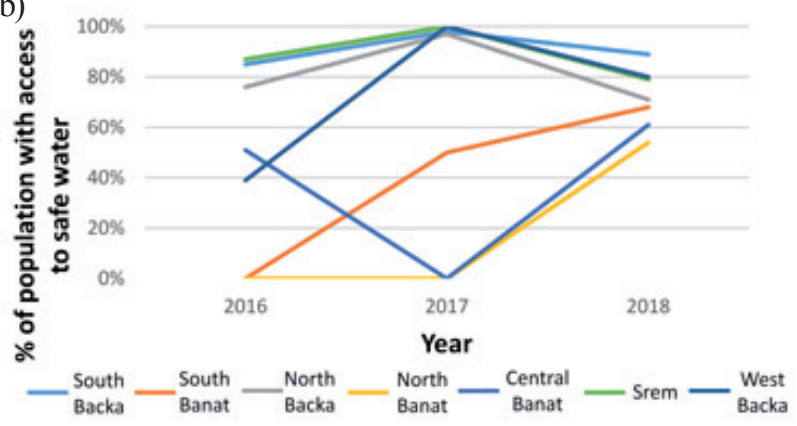

Fig. 6. a) Cancer rates by county, b) percentage of the population with access to safe water.

As previously mentioned, only a part of one county in the AP Vojvodina has its population supplied with purified chlorinated water, but Fig. 6b) shows that the percentage of the population with access to safe water has increased, apart from two counties. In 2016 and 2017, the North Banat county population had no access to safe drinking water, but in 2018 that percentage rose to $54 \%$. This is also the biggest improvement when it comes to access to safe drinking water by all counties in the AP Vojvodina in the period from 2016 to 2018. The percentage of the population in North Bačka county with access to safe water dropped down from $76 \%$ in

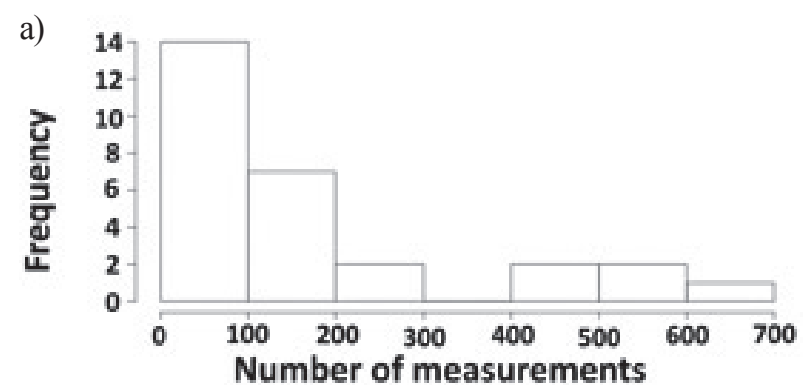

b)

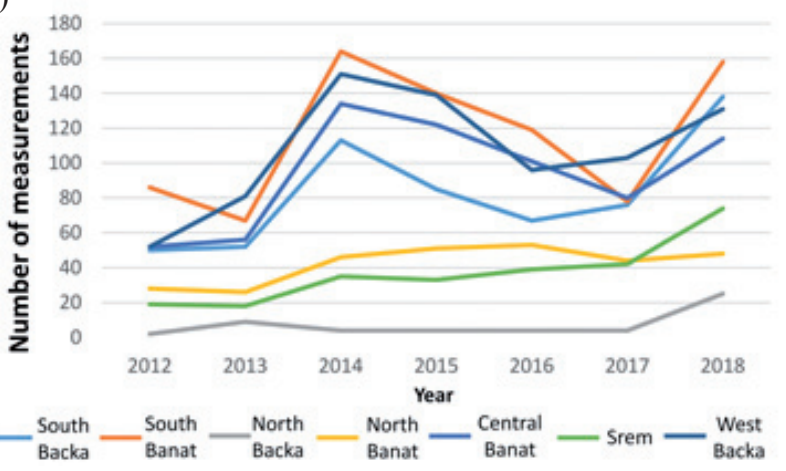

Fig. 7. a) Histogram of the summarised arsenic concentration measuring numbers, b) Number of measurements by county.

2016 to $71 \%$ in 2018. Also in 2016, in Srem county, $87 \%$ of the population had access to safe water, but in 2018 that percentage dropped down to $79 \%$. This is the largest decrease in terms of accessible safe water in the AP Vojvodina in the mentioned period. There is a situation that, although in one county there is a municipal water supply system, it is forbidden to use tap water even for bathing due to high arsenic concentrations in this water supply system. The geographical distribution of water access is shown in Fig. 8b).

The intensity of monitoring increased over the period, suggesting an increase in drinking water monitoring, i.e. more samples per capita monitored [26],

Table 1. Temporal distribution of the elements associating arsenic concentrations with cancer rates.

\begin{tabular}{|c|c|c|c|c|c|c|c|c|}
\hline Year & Element & $\begin{array}{l}\text { South } \\
\text { Bačka }\end{array}$ & $\begin{array}{l}\text { South } \\
\text { Banat }\end{array}$ & $\begin{array}{l}\text { North } \\
\text { Bačka }\end{array}$ & $\begin{array}{l}\text { North } \\
\text { Banat }\end{array}$ & $\begin{array}{c}\text { Central } \\
\text { Banat }\end{array}$ & Srem & $\begin{array}{l}\text { West } \\
\text { Bačka }\end{array}$ \\
\hline \multirow{4}{*}{2016} & Number of measurements & 67 & 119 & 4 & 53 & 101 & 39 & 96 \\
\hline & Mean arsenic conc. $(\mu \mathrm{g} / \mathrm{l})$ & 5.46 & 3.27 & 11.1 & 64.07 & 3.14 & 1.47 & 14.3 \\
\hline & Cancer rates (rate per 100,000 ) & 229.2 & 229.7 & 274.4 & 279.6 & 249.9 & 260.9 & 301.4 \\
\hline & Water access $(\%)$ & 15 & 100 & 24 & 100 & 49 & 13 & 61 \\
\hline \multirow{4}{*}{2017} & Number of measurements & 76 & 78 & 4 & 44 & 80 & 42 & 103 \\
\hline & Mean arsenic conc. $(\mu \mathrm{g} / \mathrm{l})$ & 4.16 & 4.69 & 15.45 & 49.45 & 2.87 & 1.41 & 12.13 \\
\hline & Cancer rates (rate per 100,000$)$ & 229.2 & 254.2 & 289.4 & 287.5 & 262.4 & 272.2 & 302.4 \\
\hline & Water access $(\%)$ & 2 & 50 & 3 & 100 & 100 & 0 & 0 \\
\hline \multirow{4}{*}{2018} & Number of measurements & 138 & 158 & 25 & 48 & 114 & 74 & 131 \\
\hline & Mean arsenic conc. $(\mu \mathrm{g} / \mathrm{l})$ & 6.37 & 9.62 & 40.15 & 75.23 & 3.32 & 3.13 & 24.65 \\
\hline & Cancer rates (rate per 100,000 ) & 248.2 & 268.9 & 313.5 & 303.3 & 315.4 & 296 & 357.6 \\
\hline & Water access $(\%)$ & 11 & 32 & 29 & 46 & 39 & 21 & 20 \\
\hline
\end{tabular}




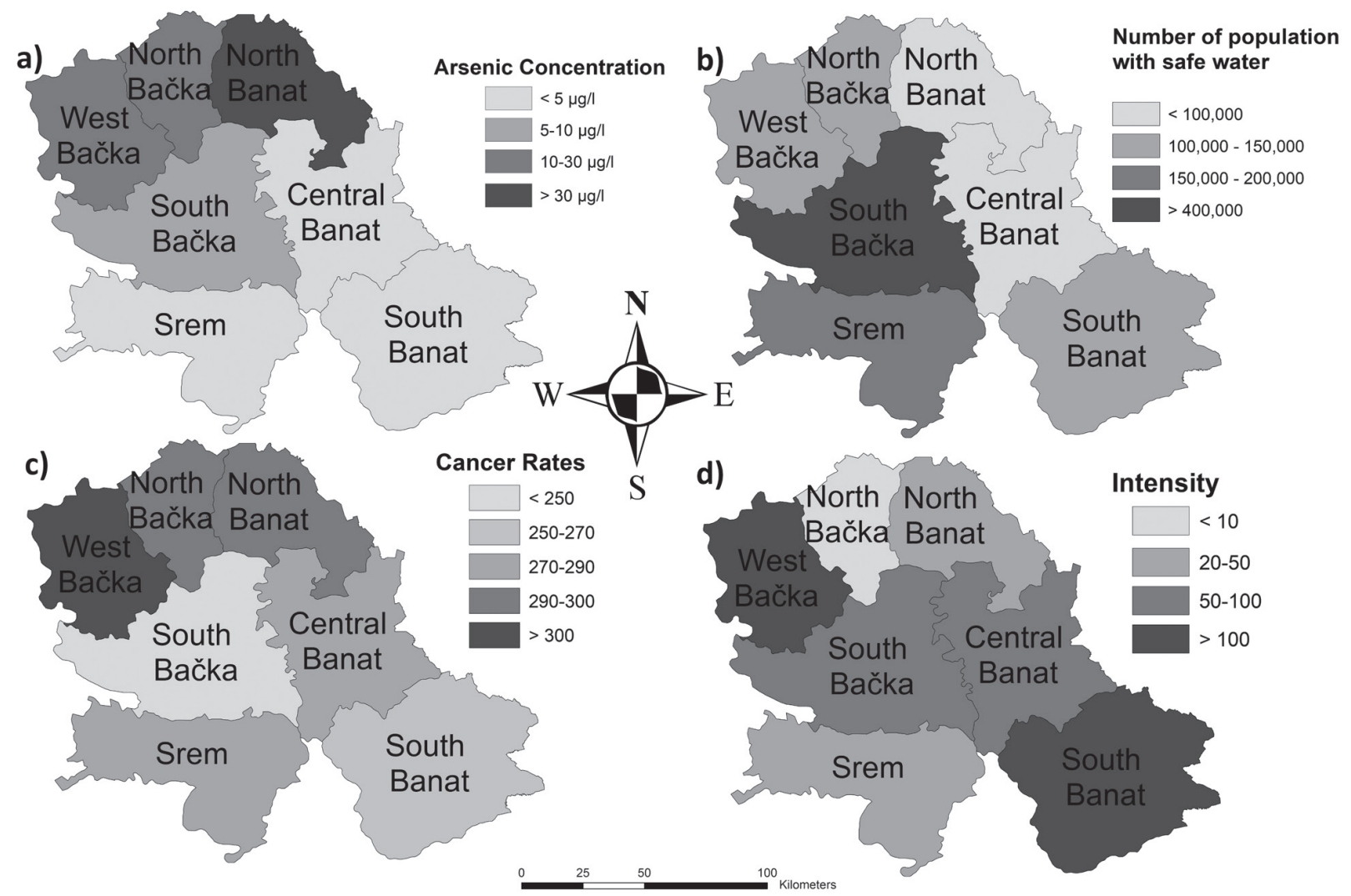

Fig. 8. Spatial distribution of: a) mean arsenic concentrations, b) population with safe drinking water, c) cancer rates, d) number of measurements, i.e. intensity.

which could be seen in Fig. 7. Fig. 7a) shows a histogram of the summarized number of arsenic concentration measurements and Fig. 7b) shows the number of arsenic concentrations by county during the period from 2012 to 2018. The highest number of As concentration measurements was recorded in South Banat county with 164 measurements in 2014, but if we consider the average number of measurements per year in all counties, 2018 is the year with the highest average numbers of measurements - 98, followed by 2014 with 92 measurements on average. The highest increase in the number of arsenic concentration measurements was recorded in West Bačka county, from 52 measurements in 2012 to 151 in 2014, but the number of measurements in 2018 dropped to 131. The lowest number of As concentration measurements was recorded in North Bačka county with 2 measurements in 2012, but that number rose to 25 in 2018. The geographical distribution of this element is shown in Fig. 8d).

The first model, as illustrated in Fig. 3, was developed to assess the relationships between the cancer rates and the arsenic concentration in surface and ground water and water access. Table 2 presents the results of this model fit, and Fig. 9 shows the relation between cancer rates, mean arsenic concentrations, and water access.

The Poisson regression model suggests that [26] the relation between arsenic concentration and water access is significant. The P-value for this element was 0.0027 and even with the P-value set to 0.01 for a stricter model, this variable should remain within the model $(0.0027<0.01)$. It is assumed that if the arsenic concentration in ground and surface water is high, then the drinking water quality will be low. The model particularly indicates that the increase in the arsenic concentration and the decrease in water access correspond to the annual increase in the cancer rates. Figure 10 shows the relation between the cancer rates and the average mean arsenic concentration values. In testing the Poisson regression for this model, using equation (1), two variables were used - the average mean arsenic concentration value $\left(a_{-}\right)$and the number of the population with access to non-safe drinking water (b_):

$$
\log \left(\mathrm{o}_{-}\right)=\mathrm{n}+\mathrm{k} 1 *\left(\mathrm{a}_{-}\right)+\mathrm{k} 2 *\left(\mathrm{~b}_{-}\right)
$$

where (o_) is the lung and bladder cancer rate, $\mathrm{n}$ is the intercept, and $\mathrm{k} 1$ and $\mathrm{k} 2$ are the numeric regression coefficients.

Using the above mentioned formula for the Poisson regression model gives the formula for fitting Model 1:

$\log \left(o_{-}\right)=5.633+0.002357 *\left(a_{-}\right)-0.000005769 *\left(b_{-}\right)$

Fig. 4 illustrates the second model which assesses the relationship between the action element, i.e. intensity and the effect element i.e. cancer rates. 


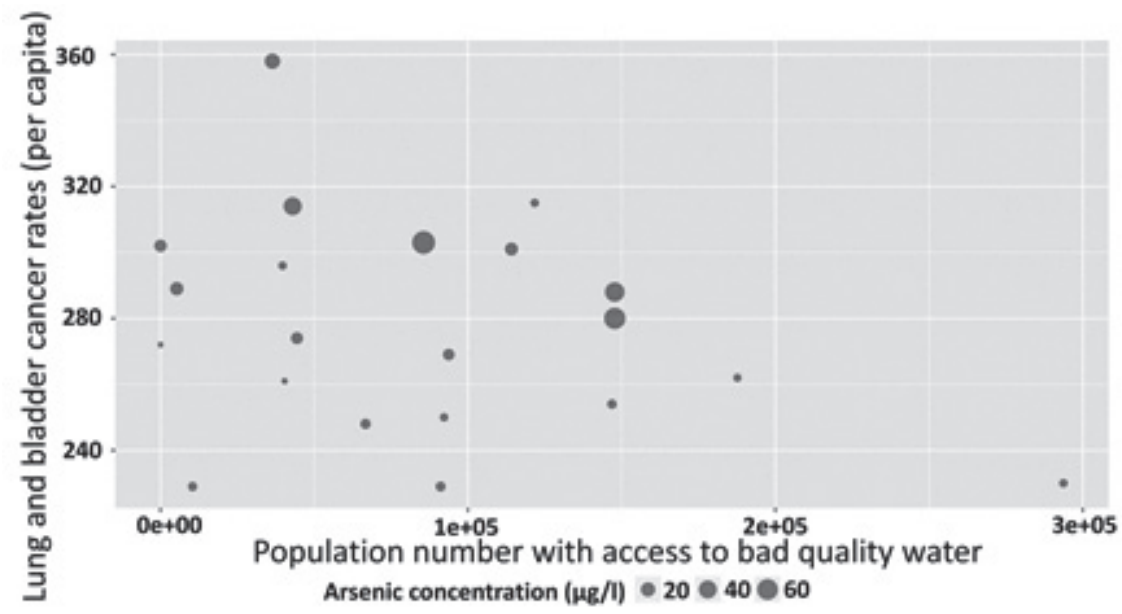

Fig. 9. Histogram of the Cancer rates-Arsenic concentration-Water Access relation.

Table 2. Cancer rates - Poisson Regression Model 1: Parameter Estimates, SE and P-values.

\begin{tabular}{|c|c|c|c|}
\hline Model parameters & Parameters estimates & SE & P-values \\
\hline Intercept & 5.633 & 0.02261 & $2 \times 10^{-16}$ \\
\hline Arsenic concentration & 0.002357 & 0.0006026 & $9.19 \times 10^{-5}$ \\
\hline Water access & -0.0000005769 & 0.0000001923 & $2.7 \times 10^{-3}$ \\
\hline
\end{tabular}

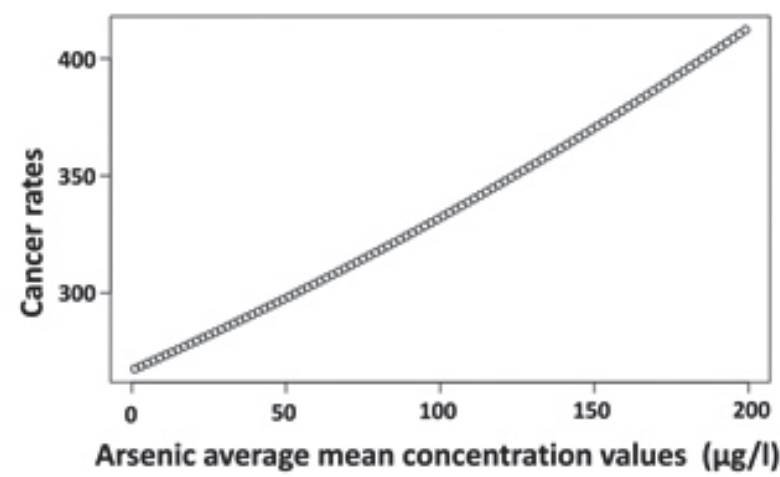

Fig. 10. Relation between the cancer rates and the average mean arsenic concentration values.
After the above mentioned explicit function had been applied, the measured correlation coefficient, obtained using monitoring data by county and the summarised data for the whole AP Vojvodina, showed a significant linear relation due to its value of 0.91 , which suggests the presence of a strong positive correlation. However, when only the relation between the cancer rates and the summarised monitoring data for the AP Vojvodina was tested, the multiple R-squared coefficient value was 0.2448 , which suggests that the model was not appropriate and, therefore, for the purpose of testing this model, this study used the Poisson regression model with monitoring county-level data only. Table 3, showing the coefficients from this model fitting, suggests that an increase in the cancer rates is associated with an increase in the intensity of monitoring.

Table 3. Cancer rates - Poisson Regression Model 2: Parameter Estimates, SE and P-values.

\begin{tabular}{|c|c|c|c|c|}
\hline \multicolumn{2}{|c|}{ Model parameters } & Parameters estimates & SE & P-values \\
\hline \multirow{2}{*}{ Intercept } & 6.4486454 & 0.0519049 & $2 \times 10^{-16}$ \\
\hline \multirow{4}{*}{$\begin{array}{c}\text { Number of } \\
\text { measurements }\end{array}$} & South Banat & -0.7493025 & 0.0395919 & $2 \times 10^{-16}$ \\
\cline { 2 - 5 } & North Bačka & -0.9663071 & 0.0597370 & $2 \times 10^{-16}$ \\
\cline { 2 - 5 } & North Banat & -1.1427936 & 0.0505275 & $2 \times 10^{-16}$ \\
\cline { 2 - 5 } & Central Banat & -1.0889142 & 0.0429148 & $2 \times 10^{-16}$ \\
\cline { 2 - 5 } & Srem & -0.4938586 & 0.0415714 & $2 \times 10^{-16}$ \\
\cline { 2 - 5 } & West Bačka & -0.9674489 & 0.0414755 & $2 \times 10^{-16}$ \\
\hline
\end{tabular}




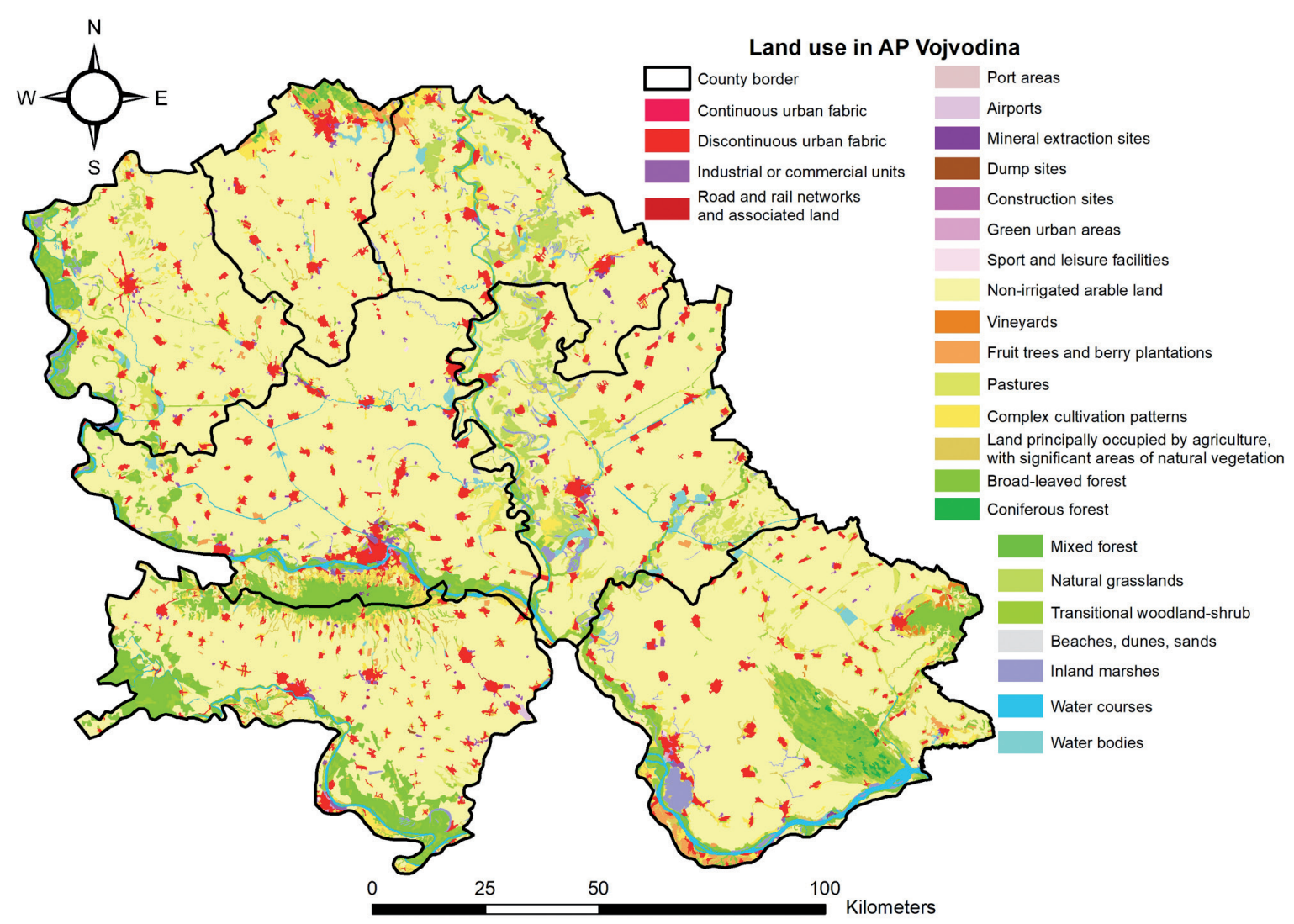

Fig. 11. Land use in AP Vojvodina (according to CORINE Land Cover) [48].

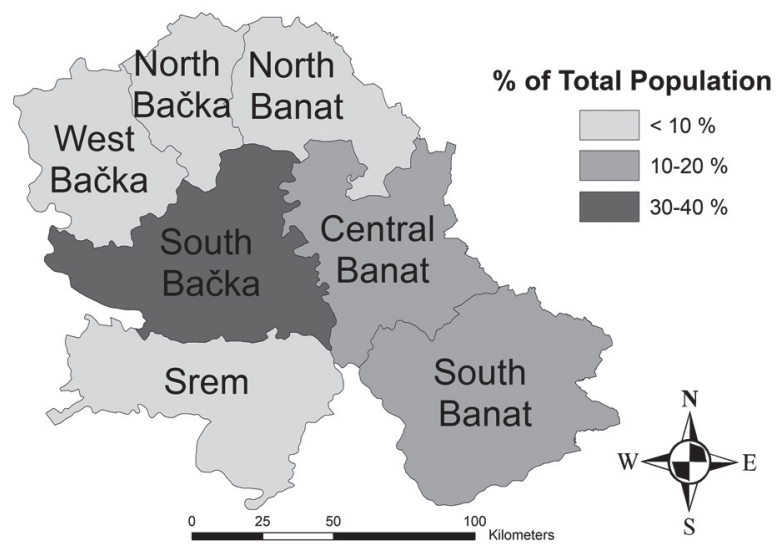

Fig. 12. Population distribution by counties in AP Vojvodina.

Both models confirm the intrinsic validity of the four [26] elements. Their relationship within the DPSEEA framework is also confirmed. The linear function tested in the second model suggests that the relationship is not a simple, linear relationship between the four elements but rather a more complex interaction [26].

\section{Discussion}

This type of study could assist in evaluating the effectiveness of policies and could facilitate prioritizing resources [26]. Also, it offers a systematic approach to solving the problem of harmful effects of high arsenic concentrations in ground and surface water on population health. However, it should be emphasized that these observed associations apply only at the county level for a short period of time [26]. The linkage analyses in this study highlight some data quality issues. It has not been possible to quantify the error in the key quality parameters such as data quality and consistency [26] in this study. Regarding consistency, the observed period in this study was from 2012 to 2018, but the data on cancer rates varies. From 2012 to 2015, the data on cancer rates is available only at the level of the Province as a whole, and from 2016 to 2018, the data is available at the county level. Therefore, as the linkage analyses in this study suggested to use data at the county level, all other elements were also presented at the county level from 2016 to 2018, although the data at all local levels had been collected for a longer period.

One of the main data quality issues with [26] environmental studies using routinely collected data is that the data being used has been collected primarily for other purposes [26]. One of the consequences is that the study relies heavily on the definitions applied by the organisations collecting the data [26]. Therefore, this study used the data published by the SEPA for As concentrations in water (defined as the state element of the DPSEEA framework), the data published by the Institute of Public Health of Vojvodina for population 
access to safe water (defined as the exposure element of the DPSEEA framework), the data published by the Institute of Public Health of Serbia "Dr Milan Jovanović Batut" and the Institute of Public Health of AP Vojvodina for the cancer rates (defined as the effect element of the DPSEEA framework), and the data published by the SEPA for monitoring intensity (defined as the action element of the DPSEEA framework). Hence, three different organisations were data sources used in this study.

Publicly available data on the population health presented at a local level could have a financial impact. Therefore, in linkage analyses of cancer rates and a number of population with access to safe drinking water at a local level, it is possible to act locally instead at the whole county level in case the application of the model presented in this study suggests that some local area is affected with a high number of cancer rates and the population does not have access to safe drinking water. Not to mention a positive financial impact of lowering the monitoring intensity and health care costs for the cancer affected population. For example, in North Banat county, As concentration is the highest recorded and the number of the population with access to safe drinking water is the lowest in the Province. Although the average number of new cancer cases in this district is not the highest, it is possible to reduce new cancer cases if municipality water supply systems are provided and properly installed. Also, it is clear that in South Bačka county (where the highest percentage of the population with access to safe water is located), the smallest rate of new cancer cases can be observed, although this county has the highest population in the Province.

Due to the lack of population health data at the local level, it is necessary to conduct thorough studies on the population health in the counties with a very high arsenic concentration in surface and ground water. As the linkage analysis in this study showed, the relation between the elements is not simple and straightforward, but rather of a complex form, inviting for further studies on possible cancer causes. It is not possible to say that only one factor, such as water, influences lung or bladder cancer occurrence. To be precise, multiple factors can influence cancer occurrence. Therefore, it is necessary that experts in different fields participate in further studies in order to have a comprehensive and integrated approach, which this study has already showed through the integrated relation between environmental, statistic, and population health data.

As mentioned before, not only does a high arsenic concentration in surface and ground water harm human health, but a high arsenic concentration naturally present in the soil is harmful as well. Using surface water with a high arsenic concentration for irrigation is also considered very harmful to human health due to the possibility of getting arsenic directly or indirectly through the land to food. It is possible that land use is the main driving force influencing drinking water quality. Land use patterns exert different pressures on source water [26]. The main pressures in the AP Vojvodina are agriculture use and urbanisation. In Figure 11, it is clear that urban areas cover 3\% of the land area and nearly $79 \%$ of the land area is used for agriculture. In addition, Figure 12 shows that almost a third (32\%) of all of the population in the AP Vojvodina is situated in one county and the rest of the Province population is unevenly distributed. This translates to different water quality management strategies being needed for urban and rural areas [26] since the main distinction between urban and rural land use is that urban land use is associated with point source pollution, whereas rural land use is associated with diffuse water pollution [26]. Bearing in mind the fact that most of the land in the Province is used for agriculture, it is clear that vast areas are exposed to arsenic influence. It is also found that four (out of seven) districts in the Province have recorded higher arsenic concentration values in water, exceeding the defined threshold values established by the Serbian regulations.

\section{Conclusions}

The study demonstrates how four elements of the DPSEEA model are used to relate the effect of arsenic to the cancer rate increase in the counties of the Autonomous Province of Vojvodina (Northern Serbia), which can impede their development significantly. The use of As concentrations, water access, lung and bladder cancer rates and monitoring intensity within the DPSEEA framework provided comparisons across regions within the Province over time through an integrated assessment of both environmental and health information, spatially and temporally. This study also showed the efficiency of the DPSEEA framework and its elements, through their ability to connect various datasets, managed by different public organisations, using regularly collected data. As it is shown in this study, this could lead to a comprehensive approach in understanding the relationship between the environmental risk factors and population health. Also, this is the first study in Serbia in which both types of data have been collated and analysed at the level of the Province.

One of the recommendations from this study would be to examine the influence of driving forces and pressures on population health using the DPSEEA framework. This is possible only if experts of different profiles work together on complex research projects oriented towards the investigation of arsenic influence on population health.

\section{Acknowledgments}

The authors would like to thank Igor Popović for his statistical support. 


\section{Conflict of Interest}

The authors declare no conflict of interest

\section{References}

1. MATIĆ B., DEJANOVIĆ S., KNEŽEVIĆ T., ŽIVADINOVIĆ D., RAKIĆ U. Environmental health indicators in the Republic of Serbia in 2015, Institute of Public Health of Serbia "Dr Milan Jovanović Batut": Belgrade, Serbia, 5, 2016 [In Serbian].

2. MATIĆ B., JOVANOVIĆ D., DEJANOVIĆ S., RAKIĆ $\mathrm{U}$. Environmental health indicators in the Republic of Serbia in 2012, Institute of Public Health of Serbia "Dr Milan Jovanović Batut”: Belgrade, Serbia, 13, 2013 [In Serbian].

3. KRIČKOVIĆ E. Cause-effect relationship between air quality and public health in the city of Novi Sad based on the DPSEEA model, Military Technical Courier, Ministry of Defence of the Republic of Serbia: Belgrade, Serbia, $\mathbf{6 9}$ (1), 109, 2021.

4. WORLD HEALTH ORGANIZATION. Environmental health indicators for Europe: A pilot indicator based report, WHO Regional Office for Europe: Copenhagen, Denmark, $4,2004$.

5. WORLD CANCER RESEARCH FUND (2021). Available at: https://www.wcrf.org/dietandcancer/global-cancer-databy-country/ (accessed on 5.06.2021)

6. ILIĆ M., ILIĆ I. Cancer mortality in Serbia, 1991-2015: an age-period-cohort and joinpoint regression analysis, CANCER COMMUNICATIONS, 38, 10, 2018.

7. UNICEF, WHO. Arsenic primer: Guidance on the Investigation \& Mitigation of Arsenic Contamination, New York: UNICEF, 13, 2018.

8. UNITED STATES, ENVIRONMENTAL PROTECTION AGENCY. Arsenic occurrence in public drinking water supplies, Washington, D.C.: EPA; Report EPA815-R-00-023, 8, 2000.

9. HURTADO-JIMENEZ R., GARDEA-TORRESDEY J. Arsenic in drinking water in the Los Altos de Jalisco region of Mexico. Rev Panam Salud Publica/Pan Am J Public Health, 20(4), 237, 2006.

10. SMITH A., HOPENHAYN-RICH C., BATES M., GOEDEN H., HERTZ-PICCIOTTO I., DUGGAN H., WOOD R., KOSNETT M., SMITH M. Cancer Risks from Arsenic in Drinking Water. Environmental Health Perspectives, 97, 259, 1992.

11. ROWLAND H.A.L., OMOREGIE E.O., MILLOT R., JIMENEZ C., MERTENS J., BACIU C., HUG S.J., BERG M. Geochemistry and arsenic behaviour in groundwater resources of the Pannonian Basin (Hungary and Romania). Applied Geochemistry, 26 (1), 6, 2011.

12. THE INTERNATIONAL AGENCY FOR RESEARCH ON CANCER. Monographs on the Evaluation of Carcinogenic Risks to Humans: Some Drinking-water Disinfectants and Contaminants, including Arsenic. International Agency for Research on Cancer: Lyon, 84, 42, 2004.

13. UNITED STATES, AGENCY FOR TOXIC SUBSTANCES AND DISEASE REGISTRY. Toxicological profile for arsenic. ATSDR, Department of Health and Human Services: Atlanta, 7, 2007.

14. MANDAL BK., SUZUKI KT. Arsenic round the world: a review. Talanta, ELSEVIER, 58 (1), 201, 2002.
15. WORLD HEALTH ORGANIZATION. Environmental health criteria 224: arsenic and arsenic compounds. $2^{\text {nd }}$ ed. World Health Organization: Geneva, 34, 2001.

16. NATIONAL RESEARCH COUNCIL. Arsenic in drinking water. National Academy Press: Washington, 105, 1999.

17. INTERNATIONAL AGENNCY FOR RESEARCH ON CANCER. IARC Monographs on the Evaluation of the Carcinogenic Risk of Chemicals to Man: Some Metals and Metallic Compounds. International Agency for Research on Cancer: Lyon, 23, 1980.

18. INTERNATIONAL AGENNCY FOR RESEARCH ON CANCER. IARC: A Review of Human Carcinogens. C. Metals, Arsenic, Fibres and Dusts. International Agency for Research on Cancer: Lyon, 50, 2012.

19. SAINT-JACQUES N., PARKER L., BROWN P., DUMMER JB T. Arsenic in drinking water and urinary tract cancers: a systematic review of 30 years of epidemiological evidence. Environmental Health, 13 (44), 29, 2014.

20. AHMAD AKHTAR S., SAYED ULLAH SALIM M.H., BARU S., KHAN HAQUE M., FARUQUEE M.H., JALIL A., HADI ABDUL S., TALUKDER KABIR H. Arsenic in Drinking Water and Pregnancy Outcomes. Environmental Health Perspectives, 109 (6), 631, 2001.

21. CHEN C.J., CHEN C.W., WU M.M., KUO T.L. Cancer potential in liver, lung, bladder and kidney due to ingested inorganic arsenic in drinking water. Br. J. Cancer, 66, 888, 1992.

22. GENTRY-SHIELDS J., BARTRAM J. Human health and the water environment: Using the DPSEEA framework to identify the driving forces of disease. Science of the Total Environment, 468-469, 307, 2014.

23. MORRIS G.P. Ecological public health and climate change policy. Perspectives in Public Health, 130 (1), 36, 2010.

24. MORRIS GP. New approaches to problem framing in environmental health: application to water. Public Health, 124 (11), 609, 2010.

25. WAHEED B., KHAN F., VEITCH B. Linkage-based frameworks for sustainability assessment: making a case for Driving Force-Pressure-State-Exposure-EffectAction (DPSEEA) frameworks. Sustainability, 1, 441, 2009.

26. KHAN R., PHILLIPS D., FERNANDO D., FOWLES, J., LEA R. Environmental Health Indicators in New Zealand: Drinking Water - A Case Study. Eco Health 4, 63, 2007.

27. WORLD HEALTH ORGANIZATION. Guidelines for Drinking-water Quality: fourth edition incorporating the first addendum, World Health Organization: Geneva, 315, 2017.

28. UNITED NATIONS CHILDREN'S FUND, WORLD HEALTH ORGANIZATION. Arsenic primer: Guidance on the Investigation \& Mitigation of Arsenic Contamination, 28, 2018.

29. OFFICIAL GAZETTE OF THE REPUBLIC OF SERBIA Regulation on limit values of pollutants in surface and groundwater and sediment and deadlines for reaching them (50/2012) Official Gazette of the Republic of Serbia: Belgrade, Serbia, 2012 [In Serbian].

30. MINISTRY OF ENVIRONMENTAL PROTECTION REPUBLIC OF SERBIA, ENVIRONMENTAL PROTECTION AGENCY. Surface and ground water quality test results for 2018. Ministry of Environmental Protection Republic of Serbia, Environmental Protection Agency: Belgrade, Serbia, 68-391, 2019 [In Serbian].

31. MINISTRY OF ENVIRONMENTAL PROTECTION REPUBLIC OF SERBIA, ENVIRONMENTAL 
PROTECTION AGENCY. Surface and groundwater quality test results for 2017. Ministry of Environmental Protection Republic of Serbia, Environmental Protection Agency: Belgrade, Serbia, 55-307, 2018 [In Serbian].

32. MINISTRY OF ENVIRONMENTAL PROTECTION REPUBLIC OF SERBIA, ENVIRONMENTAL PROTECTION AGENCY. Surface and groundwater quality test results for 2016. Ministry of Environmental Protection Republic of Serbia, Environmental Protection Agency: Belgrade, Serbia, 57-322, 2017 [In Serbian].

33. MINISTRY OF AGRICULTURE AND ENVIRONMENTAL PROTECTION REPUBLIC OF SERBIA, ENVIRONMENTAL PROTECTION AGENCY. Surface and ground water quality test results for 2015 . Ministry of Agriculture and environmental protection Republic of Serbia, Environmental Protection Agency: Belgrade, Serbia, 59-358, 2017 [In Serbian].

34. MINISTRY OF AGRICULTURE AND ENVIRONMENTAL PROTECTION REPUBLIC OF SERBIA, ENVIRONMENTAL PROTECTION AGENCY. Surface and ground water quality test results for 2014. Ministry of Agriculture and environmental protection Republic of Serbia, Environmental Protection Agency: Belgrade, Serbia, 69-429, 2015 [In Serbian].

35. MINISTRY OF AGRICULTURE AND ENVIRONMENTAL PROTECTION REPUBLIC OF SERBIA, ENVIRONMENTAL PROTECTION AGENCY. Surface and ground water quality test results for 2013. Ministry of Agriculture and environmental protection Republic of Serbia, Environmental Protection Agency: Belgrade, Serbia, 79-375, 2014 [In Serbian].

36. MINISTRY OF AGRICULTURE AND ENVIRONMENTAL PROTECTION REPUBLIC OF SERBIA, ENVIRONMENTAL PROTECTION AGENCY. Surface and ground water quality test results for 2012. Ministry of Agriculture and environmental protection Republic of Serbia, Environmental Protection Agency: Belgrade, Serbia, 75-423, 2013 [In Serbian].

37. STATISTICAL OFFICE OF THE REPUBLIC OF SERBIA. Population by age and gender, by settlements in 2011. Statistical Office of the Republic of Serbia: Belgrade, Serbia, 2012 [In Serbian].

38. INSTITUTE OF PUBLIC HEALTH OF VOJVODINA. Population health status of Vojvodina in 2018 and contributions. Institute of Public Health of Vojvodina: Novi Sad, Serbia, 54-55, 2019 [In Serbian].
39. INSTITUTE OF PUBLIC HEALTH OF VOJVODINA. Population health status of Vojvodina in 2017 and contributions. Institute of Public Health of Vojvodina: Novi Sad, Serbia, 41-42, 2018 [In Serbian].

40. INSTITUTE OF PUBLIC HEALTH OF VOJVODINA. Population health status of Vojvodina in 2016 and contributions. Institute of Public Health of Vojvodina: Novi Sad, Serbia, 32, 2017 [In Serbian].

41. INSTITUTE OF PUBLIC HEALTH OF VOJVODINA. Population health status of Vojvodina in 2015 and contributions. Institute of Public Health of Vojvodina: Novi Sad, Serbia, 31, 2016 [In Serbian].

42. INSTITUTE OF PUBLIC HEALTH OF VOJVODINA. Population health status of Vojvodina in 2014 and contributions. Institute of Public Health of Vojvodina: Novi Sad, Serbia, 28, 2015 [In Serbian].

43. INSTITUTE OF PUBLIC HEALTH OF VOJVODINA. Population health status of Vojvodina in 2013 and contributions. Institute of Public Health of Vojvodina, Novi Sad, Serbia, 128, 2014 [In Serbian].

44. INSTITUTE OF PUBLIC HEALTH OF VOJVODINA. Population health status of Vojvodina in 2012 and contributions. Institute of Public Health of Vojvodina: Novi Sad, Serbia, 68, 2013 [In Serbian].

45. INSTITUTE OF PUBLIC HEALTH OF SERBIA "DR MILAN JOVANOVIĆ BATUT". Malignant cancers for the Republic of Serbia in 2018. Institute of Public Health of Serbia "Dr Milan Jovanović Batut": Belgrade, Serbia, 22-24, 2020 [In Serbian].

46. INSTITUTE OF PUBLIC HEALTH OF SERBIA "DR MILAN JOVANOVIĆ BATUT". Malignant cancers for the Republic of Serbia in 2017. Institute of Public Health of Serbia "Dr Milan Jovanović Batut": Belgrade, Serbia, 15-17, 2020 [In Serbian].

47. INSTITUTE OF PUBLIC HEALTH OF SERBIA "DR MILAN JOVANOVIĆ BATUT". Malignant cancers for the Republic of Serbia in 2016. Institute of Public Health of Serbia "Dr Milan Jovanović Batut": Belgrade, Serbia, 15-17, 2020 [In Serbian].

48. EUROPEAN ENVIRONMENT AGENCY (EEA) UNDER THE FRAMEWORK OF THE COPERNICUS PROGRAMME. Corine Land Cover (CLC) 2018, Version 2020 20ul. Available online: https://land.copernicus.eu/ pan-european/corine-land-cover/clc2018 (accessed on 1 August 2021). 